\title{
Ensino de língua materna: dificuldades e necessidades formativas apontadas por professores na Educação Fundamental ${ }^{1}$
}

\section{Teaching of mother tongue: difficulties and formative needs as stated by Elementary School teachers}

\author{
Ana Luzia Videira Parisotto ${ }^{2}$ \\ Renata Portela Rinaldi ${ }^{2}$
}

\begin{abstract}
RESUMO
Há muitos desafios postos ao professor para o ensino de língua materna na perspectiva da alfabetização e do letramento como práticas sociais. No caso específico do município de Presidente Prudente, torna-se essencial compreender como ocorre o processo de formação continuada dos professores atuantes nos anos iniciais do Ensino Fundamental para que sejam pensadas ações formativas, tanto no âmbito do sistema municipal quanto nas escolas, que enfatizem o ensino de língua materna. Nesse sentido, este artigo objetiva refletir sobre a formação do professor dos anos iniciais do Ensino Fundamental, a partir das dificuldades e das necessidades formativas apresentadas pelos docentes com relação ao ensino de língua materna. Trata-se de uma pesquisa de base qualitativa, financiada pelo CNPq, por meio da qual analisamos os dados referentes a 22 escolas vinculadas à Secretaria de Educação do município, no que diz respeito às respostas dos professores emitidas por meio de questionários. Para este artigo, estabelecemos um recorte com o intuito de apresentar os dados relativos às respostas a duas questões dentre as que compuseram o questionário respondido pelos professores: uma referente às dificuldades que enfrentam para o ensino de língua materna e
\end{abstract}

DOI: $10.1590 / 0104-4060.45125$

1 Pesquisa financiada pelo Conselho Nacional de Desenvolvimento Científico e Tecnológico (CNPq), por meio do processo $\mathrm{n}^{\circ} 472024 / 2014$.

2 Universidade Estadual Paulista "Júlio de Mesquita Filho", Faculdade de Ciências e Tecnologia de Presidente Prudente. Presidente Prudente, São Paulo, Brasil. Rua Roberto Simonsen, no 305. Jardim das Rosas. CEP: 19060-900.E-mails: analu.videira@uol.com.br; renata.rinaldi@fct.unesp.br 
outra que diz respeito às necessidades formativas para este ensino. $\mathrm{O}$ que os participantes da pesquisa apontam como principais dificuldades relacionadas ao ensino de língua materna comparecem também no que evidenciam como necessidades formativas.

Palavras-chave: ensino de língua materna; formação docente; necessidades formativas.

\begin{abstract}
Schoolteachers face many challenges in the teaching of mother tongue from the viewpoint of the ability to read and write and literacy as social practices. With regard to the city of Presidente Prudente, Brazil, it is vital to understand how the continued education process occurs in the practice of Elementary School teachers in order to be able to devise new formative strategies - at both the municipal and school levels - aimed at improving the teaching of mother tongue. To that end, this study aims to reflect on the education of teachers of the first years of Elementary School based on their difficulties and formative needs vis-à-vis the teaching of mother tongue. This qualitative research - funded by $\mathrm{CNPq}$ (National Council for Scientific and Technological Development) - analyzes data collected by means of a questionnaire responded by teachers from 22 schools under the Municipal Department of Education. In order to limit the scope of the investigation, this study focuses on the participating teachers' answers to two of the questions on the questionnaire - one about difficulties they find in the teaching of mother tongue and another on their educational needs. Results indicate that the main difficulties identified by participants regarding the teaching of mother tongue are in line with their stated formative needs.
\end{abstract}

Keywords: teaching of mother tongue; teachers' education; formative needs.

\title{
Introdução
}

Este artigo provém de uma pesquisa intitulada $A$ formação do professor dos anos iniciais do Ensino Fundamental para superação do fracasso escolar: perfil teórico-metodológico e propostas para o ensino de língua materna, financiada pelo Conselho Nacional de Desenvolvimento Científico e Tecnológico (CNPq), processo $n^{\circ} 472024 / 2014$. O objetivo da pesquisa mencionada é suscitar a reflexão sobre formação docente e ensino de língua materna, no sentido de compreender as dificuldades enfrentadas cotidianamente pelo professor e quais as contribuições possíveis para a superação do fracasso escolar. Dessa forma, 
investiga aspectos profissionais, pessoais, concepções teórico-metodológicas, dificuldades para o ensino de língua materna, interesses por cursos de formação continuada, dentre outros fatores, tendo como sujeitos os professores e os gestores de 22 escolas de Ensino Fundamental do município de Presidente Prudente.

Ser capaz de ler e escrever com proficiência em língua materna é imprescindível para o desenvolvimento de qualquer pessoa inserida em uma cultura letrada. Além disso, o domínio da leitura e da escrita ajuda o sujeito a desenvolver autonomia e a superar barreiras sociais, culturais e econômicas que podem lhe ser impostas ao longo da vida. Nesse sentido, refletir sobre aspectos relacionados à formação docente e ao ensino de língua materna pode contribuir para o encaminhamento de possíveis ações que visem à superação do fracasso escolar. O que se observa, de um modo geral, é que o professor dos anos iniciais do Ensino Fundamental encontra-se sem um respaldo teórico-metodológico que norteie a sua prática. Nesse sentido, torna-se reprodutor de conteúdos programáticos desajustados da realidade do aluno, priorizando o estudo da metalinguagem, ou seja, o estudo da nomenclatura gramatical, deixando de propiciar aos seus alunos momentos de uso efetivo da língua materna.

No que diz respeito à alfabetização e letramento, para que o indivíduo seja considerado letrado, deve fazer uso de diferentes materiais escritos e compreendê-los, tornando possível a sua inserção no âmbito social. Por conseguinte, $o$ ato de ler amplia-se e passa a compreender um conjunto de habilidades que vão da simples decodificação de palavras escritas até a atribuição de sentido, ou sentidos, que as palavras podem assumir, de acordo com as situações de interação verbal.

Entender a alfabetização em um sentido relacionado tão somente à aquisição do código, dissociada do letramento, impõe uma restrição às questões da leitura e da escrita, relegando os aspectos extraescolares que efetivam a importância do uso adequado da língua, seja em situações de escrita, seja em manifestações orais. Conceber, essencialmente, que as questões do letramento não estão limitadas aos muros escolares é importante para se buscar uma efetiva mudança na cultura escolar de alfabetização.

Ao tratar das questões de letramento, Soares (2011) faz, inicialmente, uso do termo "alfabetismo", que, de acordo com ela, envolve uma:

[...] realidade social em que não basta simplesmente "saber ler e escrever": dos indivíduos já se requer não apenas que dominem a tecnologia do ler e do escrever, mas também que saibam fazer uso dela, incorporando-a a seu viver, transformando-se assim seu "estado" ou "condição", como consequência do domínio dessa tecnologia. (SOARES, 2011, p. 29). 
De acordo a autora, o letramento representa, assim, a existência de práticas de leitura e escrita, constituindo-se num conceito complexo, que abarca uma ampla gama de conhecimentos, habilidades, técnicas, valores e usos sociais.

Dessa forma, letramento implica refletir e interpretar, pois envolve a leitura e a compreensão de textos, a leitura de mundo, a compreensão da função social da escrita, incluindo o respeito às diferenças culturais e às práticas sociais que utilizam a escrita.

Como conceber que crianças cheguem ao final do primeiro ciclo do Ensino Fundamental sem compreender claramente o que leem e sem conseguir produzir textos adequados a determinadas situações comunicativas? Se partirmos do princípio de que a finalidade da educação é preparar o indivíduo para o exercício pleno da cidadania, observamos uma falha nesse processo. Como exercer a cidadania quando não se é capaz de compreender o enunciado de um texto?

Pesquisas relacionadas à formação docente têm enfatizado o percurso histórico estabelecido entre a concepção de "professor das primeiras letras" e a de professor como "agente letrador". (BORTONI-RICARDO; MACHADO; CASTANHEIRA, 2010; KLEIMAN, 2012). E é nesse caminhar que se tem marcados os avanços e as tensões no sentido de se atribuir à docência o caráter de profissão. Nesse sentido, a formação inicial e continuada de professores é investigada como forma de lançar novos olhares e novos fazeres, atentando para as novas demandas da sociedade.

Não só a formação docente pode destacar-se como relevante no ensino de língua materna, mas também as políticas educacionais. No caso específico do município de Presidente Prudente, torna-se essencial compreender como ocorre o processo de formação continuada dos professores atuantes nos anos iniciais do Ensino Fundamental para que sejam pensadas ações formativas tanto no âmbito do sistema municipal quanto nas escolas.

O recorte estabelecido para este artigo será o de apresentar e correlacionar os dados relativos a duas questões dentre as que compuseram o questionário respondido pelos professores: quais são as dificuldades que você enfrenta cotidianamente para o ensino de língua materna? Você sente necessidade de aprofundar seus conhecimentos em Língua materna para melhor ensinar? Caso responda afirmativamente, sugira temas de aprofundamento que considere importante para sua formação.

A partir desses questionamentos, objetivamos refletir sobre a formação do professor dos anos iniciais do Ensino Fundamental, no município de Presidente Prudente, de acordo com as dificuldades e as necessidades formativas apresentadas por eles, com relação ao ensino de língua materna. 


\section{Metodologia}

Trata-se de uma pesquisa de base qualitativa, por meio da qual descrevemos e analisamos os fenômenos que estão impregnados dos significados que o contexto social lhes concede. Dessa forma, os dados foram obtidos por meio de questionários aplicados a professores e gestores, bem como por análise documental.

A nossa amostra foi composta por professores e gestores de 22 escolas municipais vinculadas à Secretaria de Educação do município de Presidente Prudente.

A pesquisa foi organizada em três fases: na fase 1 realizamos a pesquisa documental em base de dados para identificar o desempenho das escolas nas avaliações externas e aplicamos os questionários em 22 duas escolas de Ensino Fundamental I do município de Presidente Prudente; na fase 2 iniciamos o processo de organização e de tabulação dos dados; finalmente, na fase 3, pretendemos desenvolver práticas formativas consideradas eficazes a partir do levantamento dos questionários.

Os questionários destinados aos docentes foram utilizados para caracterizar o perfil pessoal, o profissional e o teórico-metodológico do professor que leciona nos anos iniciais do Ensino Fundamental, bem como as dificuldades enfrentadas cotidianamente no ensino de língua materna, quais são as práticas formativas que consideram eficazes e como avaliam a contribuição da gestão escolar, com relação à superação do fracasso escolar em língua materna. No que concerne aos gestores, o questionário destinado a esse profissional abordou questões relativas às práticas formativas que consideram eficazes e à contribuição da gestão escolar no sentido de propor ações para a superação do fracasso escolar.

Os dados estão sendo tabulados e analisados à luz da análise de conteúdo (BARDIN, 2011) e do referencial teórico voltado para o ensino de língua materna e formação docente (GERALDI, 2001; IMBERNÓN, 2005; KOCH; TRAVAGLIA, 2008; KOCH, 2001; MORAIS, 2009; TARDIF; LESSARD, 2008; UNESCO, 2004), dentre outros. Já iniciamos também o processo de cadastramento de um curso de extensão, na modalidade de aperfeiçoamento, cujos enfoques incidem sobre as necessidades formativas apontadas pelos docentes. 


\section{Alguns resultados}

Para este artigo apresentaremos somente os resultados referentes às respostas emitidas por 158 professores de 22 escolas vinculadas à Secretaria de Educação do município de Presidente Prudente, correlacionando duas respostas obtidas por meio de questionário a perguntas que versavam sobre: as dificuldades que as professoras enfrentam cotidianamente para ensinar a língua materna (Gráficos 1 e 2) e as necessidade formativas para tal ensino (Gráfico 3).

Desse modo, os Gráficos 1 e 2 dizem respeito às respostas relacionadas à questão: Quais são as dificuldades que você enfrenta cotidianamente para ensinar a língua materna? Ao iniciar a análise dos dados, percebemos que algumas respostas tangenciavam as dificuldades com o ensino de língua materna e outras já abordavam temáticas mais relacionadas a tal componente curricular. Por isso, organizamos as respostas, primeiramente, em dois grandes grupos: respostas que tangenciam o ensino de língua materna e respostas que realmente dizem respeito a tal ensino, objeto de nossa pesquisa. E, a partir disso, categorizamos as respostas apresentadas e observamos a sua frequência. Vale ressaltar que os sujeitos da pesquisa poderiam elencar várias dificuldades em resposta ao que lhes fora solicitado na primeira questão com cujos resultados trabalharemos neste artigo.

Dos 158 docentes pesquisados, 12 não responderam a essa pergunta e 2 afirmaram não encontrar dificuldade alguma. Dessa forma, restou-nos observar as respostas de 144 docentes, totalizando 193 respostas, já que eles poderiam elencar mais de uma, que versavam sobre algum tipo de dificuldade de ensino. Portanto, destacamos que as respostas de 49 docentes estão encaixadas nos dois grandes grupos já citados, ou seja, os professores mencionaram tanto respostas que tangenciam o ensino de língua materna quanto respostas relativas a tal ensino; enquanto 53 referem-se apenas ao primeiro grupo e 42 exclusivamente ao segundo grupo.

Com maior frequência aparecem respostas como falta de interesse dos alunos e falta de apoio dos pais, com aproximadamente $12,4 \%$ e $10,9 \%$, respectivamente. No que diz respeito ao desinteresse dos alunos, Libâneo (2011) afirma que a investigação didática tem enfatizado algumas ações didático-pedagógicas conciliáveis com propostas educacionais de caráter emancipatório, dentre elas, destacamos como ações importantes para que o aluno se torne sujeito de sua aprendizagem e, portanto, mais interessado em participar ativamente das aulas: um papel ativo do sujeito na aprendizagem escolar; o diálogo entre professores e alunos a fim de que se tornem cúmplices perante o objeto de conhecimento; 
GRÁFICO 1 - DIFICULDADES ENFRENTADAS COTIDIANAMENTE QUE TANGENCIAM O ENSINO DE LÍNGUA MATERNA

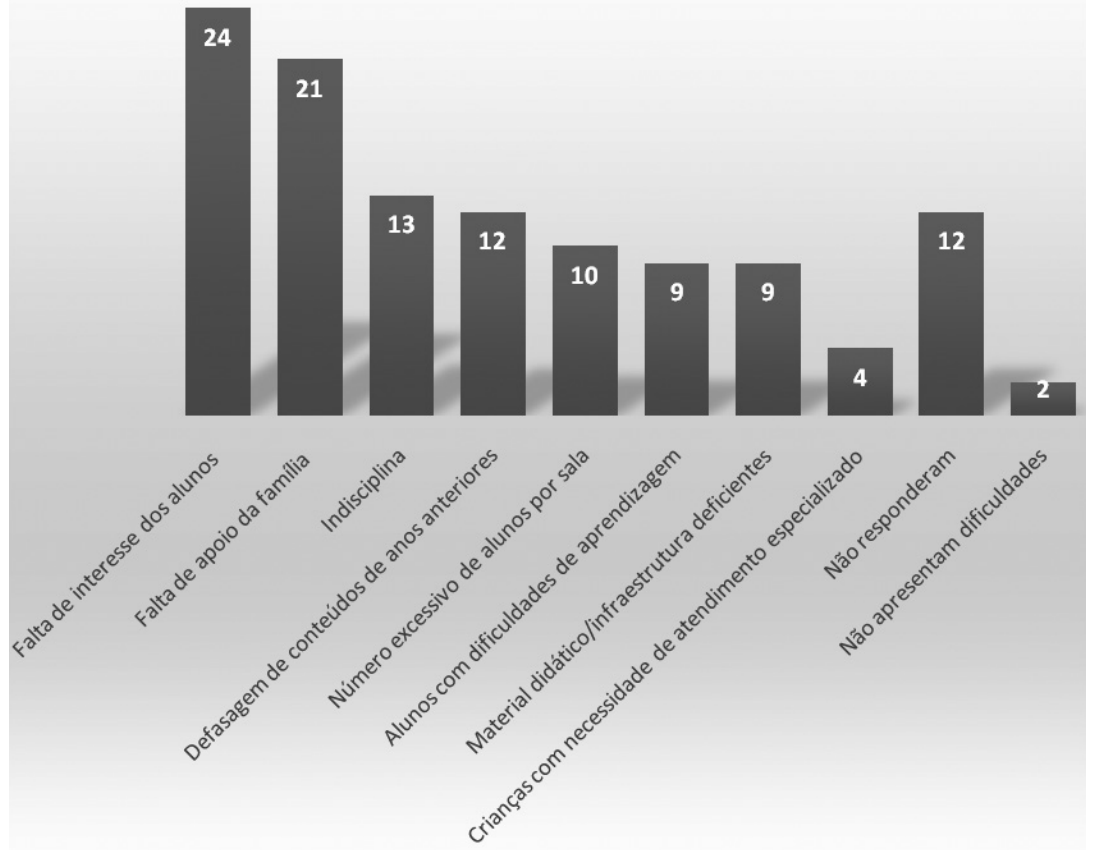

FONTE: As autoras (2016).

a construção de conceitos articulados com as representações dos alunos; uma aprendizagem que propicie o pensar criticamente; as práticas interdisciplinares; a valorização entre conhecimento científico e sua funcionalidade prática; o reconhecimento da diferença e da diversidade; a explicitação de valores e atitudes via currículo, dentre outras. Pensando no ensino de língua materna, também é interessante que as propostas de produção textual não sejam artificiais, por isso, certamente, algumas ações entre as citadas por Libâneo (2011) contribuiriam para amenizar os casos de indisciplina, outro fator mencionado pelos docentes como dificultador do ensino de língua materna.

Sobre a falta de apoio das famílias, Reali e Tancredi (2002) asseveram que o tema família-escola tem sido constantemente discutido e consideram relevante verificar as concepções que os docentes possuem sobre a família de seus alunos. Em geral, as pesquisas apontam que há um desconhecimento, 
por parte dos professores, de aspectos importantes relacionados à família dos discentes. As autoras destacam, ainda, a presença de uma visão estereotipada sobre essas famílias, já que as descrições aparecem, frequentemente, carregadas de conotações negativas. As relações entre família e escola têm-se perpetuado, ao longo dos anos, a partir de algum tipo de problema. Tal fato não contribui para que essas instituições possam formar uma parceria profícua, orientada por fatores que propiciem um avanço nas discussões e reflexões sobre os aspectos positivos e negativos presentes no cotidiano escolar. Dessa forma, por haver uma tensão entre família e escola, as colocações atinentes a essa relação são sempre carregadas de discursos defensivos e acusativos, sem que isso contribua para a reflexão sobre os reais e cotidianos problemas enfrentados pelas escolas.

Nos aspectos atinentes à defasagem de conteúdo, quando o aluno apresenta dificuldades para atingir os objetivos fixados pelo sistema escolar, há necessidade de atenção especial para que esse aluno supere tais defasagens. Weiss (2004, p. 16) explica que "[...] considera-se como fracasso escolar uma resposta insuficiente do aluno a uma exigência ou demanda da escola".

De acordo com Dourado, Oliveira e Santos (2007), o fracasso escolar pode ocorrer por problemas intrínsecos e extrínsecos ao sistema escolar. Com relação aos problemas extrínsecos, salientam-se a fome, a pobreza, a desestrutura familiar, os maus-tratos, a desnutrição, a falta de atenção, o trabalho infantil, dentre outros. Esses problemas contribuem para que a criança apresente um baixo rendimento escolar. No que diz respeito aos problemas intrínsecos, o autor destaca: os conteúdos curriculares; a metodologia utilizada pelo professor; a baixa estima do aluno, além de outros. Assim como a relação família-escola, a ideia de fracasso escolar também faz emergir discursos acusativos em que se buscam culpados: a criança, a escola, o professor e, geralmente, a família.

O Gráfico 1 ainda traz, com menor frequência, outras respostas dos professores pesquisados, tais como: número excessivo de alunos por sala, dificuldades de aprendizagem e problemas relacionados ao material didático e infraestrutura.

Apresentamos, no Gráfico 2, a seguir, as respostas dos docentes que estiveram diretamente relacionadas às dificuldades para ensinar a língua materna. Ressaltamos que os dados foram obtidos em resposta a uma questão do tipo aberta, em que os professores poderiam elencar mais de uma dificuldade que enfrentavam para tal ensino.

Com relação à alfabetização, as respostas dos professores enfatizaram a dificuldade de se trabalhar com turmas heterogêneas. Nesse caso, podemos correlacionar essa dificuldade com a mencionada no gráfico anterior, no que diz respeito ao número excessivo de alunos por sala, já que este é um fator de impacto altamente negativo para se trabalhar com turmas heterogêneas, na fase de alfabetização. Crahay (2007, p. 190) enfatiza que "[...] os alunos que 
GRÁFICO 2 - DIFICULDADES ENCONTRADAS COTIDIANAMENTE PARA O ENSINO DE LÍNGUA MATERNA

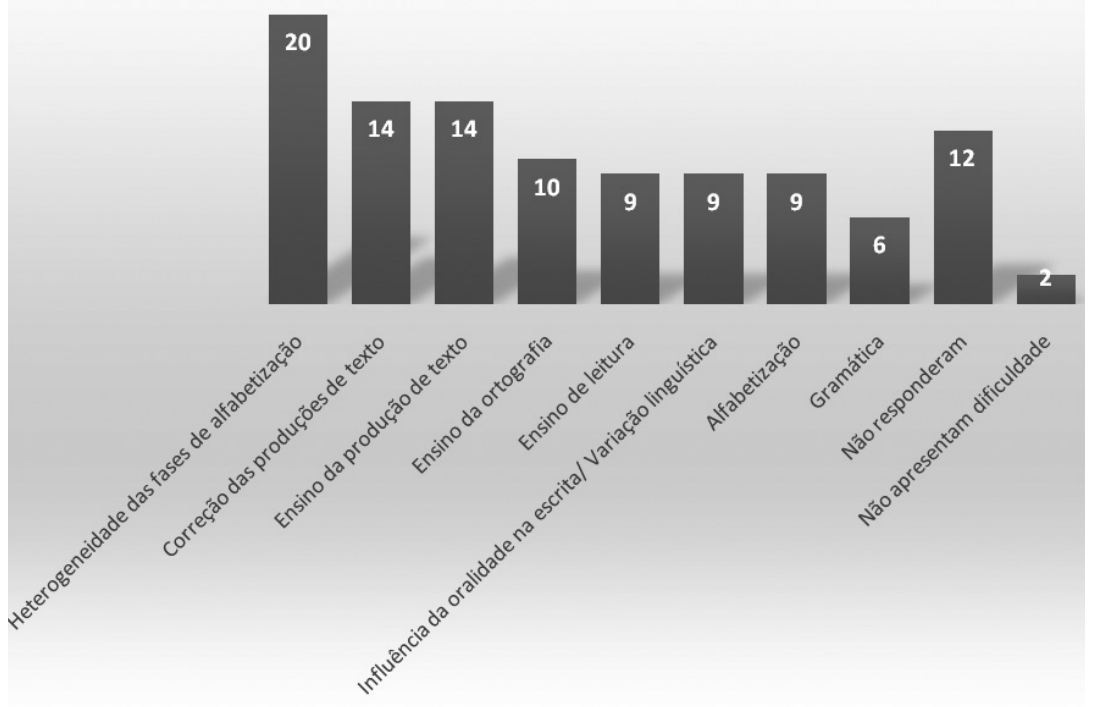

FONTE: As autoras (2016).

permanecem os 04 anos em classes de tamanho reduzido têm, no $4^{\circ}$ ano, um avanço da ordem de seis a nove meses em termos de aquisição sobre seus colegas de classes mais numerosas".

O fenômeno da heterogeneidade é inerente ao processo educativo, não apenas no período de alfabetização, mas em todos os níveis de escolarização porque as pessoas são diferentes entre si. Nesse sentido, Ferreiro e Teberosky (1989) destacam que as crianças desenvolvem maneiras próprias de escrever que, inicialmente, podem estar distantes da escrita convencional da qual se aproximam paulatinamente.

Os professores também citaram dificuldades para o ensino da produção de textos, tanto com relação à proposição de práticas significativas, quanto aos aspectos voltados à correção. Sobre o ensino da produção textual, Parisotto (2009) afirma que a metodologia para o trabalho com a produção de texto na sala de aula prevê somente os passos para uma abordagem artificial do texto, ressaltando que essa abordagem artificial, muitas vezes, está relacionada com frágeis concepções de linguagem e de texto que os docentes possuem. Como não há um propósito para a escrita, predomina, na descrição da prática metodológica, um trabalho equivocado com a produção de texto. Quanto às dificuldades re- 
lacionadas ao ensino da leitura, há muitas pesquisas que tratam dessa temática sob vários enfoques. (KLEIMAN, 1989; LERNER, 2002; JOLIBERT, 2008; BAMBERGER, 2008). E não se pode negar a relevância da escola no processo de formação leitora, considerando-se que esse espaço é visto como um ideal regulador para que o processo de leitura ocorra. Nesse sentido, Silva (2006) afirma que:

Tirar a leitura do fundo do poço em que se meteu no âmbito das escolas não é tarefa das fáceis, porque os rituais e costumes didáticos que estão aí, agindo sobre a estrutura escolar, vêm de há muitos anos. Entretanto, se a educação é também a possibilidade de renovação da virtude da esperança, não podemos assumir uma atitude derrotista, pendendo para o lado daqueles que já cruzaram os braços, achando que as escolas e os professores não mais possuem forças regeneradoras dentro de si, forças para traçar novos caminhos e novos objetivos para as ações educativas. (SILVA, 2006, p. 58).

Os professores destacaram também a dificuldade de se trabalhar com a influência da oralidade nos textos escritos, o que pode ser correlacionado com a dificuldade de se trabalhar com o ensino de ortografia, haja vista o fenômeno da variação linguística inquestionavelmente presente no período de alfabetização. Cagliari (2009) afirma que o maior número de ocorrências de erros dos alunos está ligado à transcrição fonética, ou seja, os alunos grafam as palavras de acordo com as variações dialetais que pronunciam e que usam em seu cotidiano. Enfatizamos a ideia de que não deve haver uma relação de oposição radical na relação entre a modalidade oral e a modalidade escrita. A relação deve ser de complementaridade, desfazendo preconceitos e reforçando a variação linguística no sentido de demonstrar que as duas modalidades são estruturadas, passíveis de sistematização e que variam de acordo com os graus de formalidade da situação de interação verbal. Quanto ao ensino de gramática, poucos professores citaram o trabalho com a dimensão gramatical como dificuldade.

A seguir evidenciaremos as necessidades formativas apresentadas pelos professores pesquisados com relação ao ensino de língua materna, no município de Presidente Prudente. Para tanto, analisaremos as respostas obtidas por meio da questão: Você sente necessidade de aprofundar seus conhecimentos em língua materna para melhor ensinar? Caso responda afirmativamente, sugira temas de aprofundamento que considere importantes para sua formação. 
No Gráfico 3, a seguir, apresentamos os resultados obtidos por meio das respostas de professores de 22 escolas, totalizando 158 docentes.

GRÁFICO 3 - NECESSIDADES FORMATIVAS EM CONTEÚDOS DE LÍNGUA MATERNA

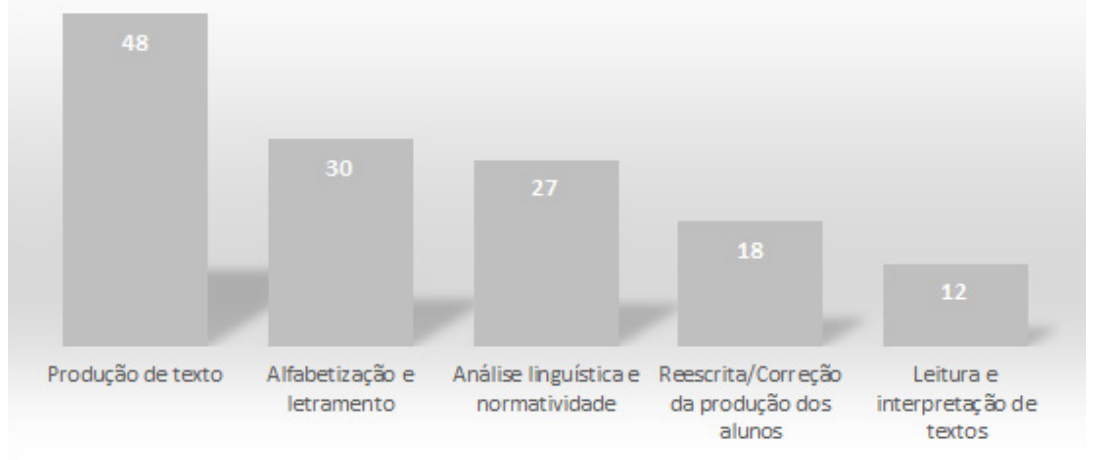

FONTE: As autoras (2016).

Ressaltamos que os sujeitos da pesquisa que sentem necessidade de aprofundar seus conhecimentos em língua materna poderiam manifestar uma ou mais necessidades formativas. Dos 158 docentes pesquisados, 21 não responderam a essa questão $(13,2 \%), 11$ responderam que sentem necessidade de aprofundar seus conhecimentos em língua materna, todavia não apontaram em quais conteúdos (6,9\%) e 3 afirmaram que não sentem essa necessidade (1,9\%). Portanto, o Gráfico 3 traz os dados relacionados às respostas dos 124 sujeitos que responderam à questão e apontaram possíveis conteúdos a serem aprofundados.

Rodrigues (2006) descreve duas perspectivas analíticas de necessidades formativas: uma mais relacionada à objetividade e, a outra, à subjetividade. A primeira diz respeito às necessidades formativas julgadas como importantes pelo analista/pesquisador, colocando, dessa forma, o professor/sujeito como objeto. Já a segunda perspectiva coloca o sujeito como protagonista do processo formativo, já que é ele quem define a sua necessidade formativa.

De todos os conteúdos elencados como passíveis de aprofundamento, os relacionados à produção de texto foram os mais citados (48 menções), seguido pelos conteúdos de alfabetização e letramento (30 menções) e análise linguística e normatividade (27 menções). Vale destacar ainda que alguns professores citaram conteúdos relacionados a processos de reescrita das produções dos alunos (18 menções) e a como ensinar leitura e interpretação de textos (12 menções).

Várias pesquisas já apontaram que uma metodologia para o trabalho com a produção textual que preveja somente passos para uma abordagem artificial do 
texto está fadada ao insucesso, pois essa abordagem artificial está relacionada às concepções de linguagem de base monológica que não propiciam uma elaboração de texto que considere as práticas sociais de escrita. (ROJO, 2009; COLELLO, 2007; PARISOTTO, 2004; GERALDI, 2001). Dessa forma, percebemos que o professor tem interesse em aprofundar seus estudos na área de produção textual tanto em aspectos que dizem respeito às condições de produção quanto àqueles relacionados à estruturação do texto, gêneros textuais, reescrita e refacção, avaliação de textos produzidos pelos alunos, dentre outros conteúdos; a fim de que possa ser superada a concepção de texto somente como atividade escolar.

Trabalhar com a produção de texto numa perspectiva da interação pressupõe que a escrita tenha uma função social e que os textos circulem dentro e fora da escola. Dessa forma, o próprio aluno aprende, desde muito cedo, a dominar o funcionamento da escrita, considerando a sua multiplicidade de situações de uso.

Um segundo tema sugerido pelos professores para aprofundamento diz respeito ao processo de alfabetização e letramento. Discutir a formação docente do ponto de vista da alfabetização e do letramento é vencer a própria crença de que a função da escola é tão somente ensinar a "ler e a escrever" e que isso se dá exclusivamente por uma alfabetização descontextualizada de um processo maior. Restringir a alfabetização somente a questões relacionadas à aquisição do código escrito impõe também restrições ao ensino da escrita e da leitura. É importante constatar que os professores pesquisados já diagnosticaram a necessidade de se apropriarem desse conhecimento e, de certa forma, também perceberam a necessidade de se repensar o ensino de língua materna, uma vez que é preciso ultrapassar a visão de língua como mero código, compreender a relação dialógica que perpassa as questões de linguagem, entender que a língua não é só letra nem só sílaba, mas que é o texto que fundamenta toda construção de sentido. Por isso é essencial que os professores dominem teorias e possam relacioná-las com as práticas que já desenvolvem em sala de aula e tenham, principalmente, condições de avaliar o que é significativo para a sua realidade escolar e o que deve ser descartado.

Quanto à análise linguística e avaliação, Costa Val et al. (2009) afirma que é importante avaliar as produções dos alunos, no sentido de fornecer-lhes a possibilidade de melhoria no desenvolvimento de habilidades linguísticas.

Para tanto, é necessário que o professor estabeleça, com muita clareza e propriedade, critérios relacionados aos padrões de textualidade: de coerência e de coesão; bem como das condições de produção, da adequação ao gênero solicitado, do domínio do sistema linguístico, dentre outros, condizentes com a etapa de ensino na qual lecione.

Os professores mencionaram, ainda que com menos intensidade, o interesse em aprofundar seus conhecimentos na área de leitura e interpretação de 
textos. Esse tema é bastante relevante, já que a escola, muitas vezes, é a principal responsável pela formação do leitor. Jolibert (2006) assevera que houve mudanças fundamentais nas concepções relacionadas ao ensino/aprendizagem da leitura, cujo processo deve ser visto como significativo, ativo, interativo e reflexivo. Para a autora, a leitura é concebida como uma busca do significado de um texto, em função dos interesses e das necessidades do leitor. Torna-se, então, imprescindível romper com práticas de leitura nas quais o ato de ler esteja relacionado somente à decodificação.

Cotidianamente, o leitor deve ser exposto a uma série de contextos e situações nas quais lê com posturas diversas. Kleiman (1989, p. 65) enfatiza o papel do leitor na construção da compreensão do texto, segundo a autora, o leitor constrói, e não apenas recebe um significado global para o texto, já que ele tenta encontrar pistas, formula hipóteses, acata ou rejeita algumas conclusões.

Correlacionando as informações apresentadas nos três gráficos, chama-nos atenção o fato de muitos docentes mencionarem dificuldades que não estejam diretamente relacionadas ao ensino de língua materna, nas respostas relativas à primeira questão. Isso demonstra que, muitas vezes, o professor se vê completamente despreparado para lidar com aspectos relacionados à indisciplina, à falta de apoio dos pais, aos problemas de aprendizagem, dentre outros fatores que impactam negativamente no desenvolvimento de seu trabalho docente. Também é possível observar que, para muitos professores ainda pode ser difícil mencionar dificuldades relativas à compreensão de conteúdo ou àquelas atinentes ao trabalho com o conteúdo, pois isso pode macular a sua profissionalidade. Em contrapartida, se atentarmos para as dificuldades que realmente dizem respeito ao ensino de língua materna, destacamos que o que eles apontam como principais dificuldades comparecem também no que evidenciam como necessidades formativas. Dessa forma, percebemos que muitos dos participantes da pesquisa têm consciência de suas fragilidades com relação ao ensino de língua materna.

\section{Considerações finais}

Os resultados deste estudo permitem-nos dizer que as principais dificuldades relacionadas ao ensino de língua materna, de acordo com os dados analisados, dizem respeito: à heterogeneidade das fases de alfabetização; a como corrigir os textos produzidos pela criança; a como ensinar a leitura, a produção de texto e a ortografia; além de como trabalhar com a oralidade no Ensino Fundamental I. Nesse sentido, os professores pesquisados destacaram vários temas sobre 
os quais têm interesse de aprofundamento: produção textual, alfabetização e letramento, análise linguística e normatividade, reescrita e avaliação de textos e leitura e interpretação textual.

Dessa forma, o processo de formação continuada de professores pode constituir-se num significativo momento para que se devolva a palavra aos sujeitos, a fim de que, num processo dialógico, tornem-se responsáveis por sua formação, enfatizando o seu contexto de trabalho, já que o conhecimento da língua materna é fundamental para que o docente dos anos iniciais do Ensino Fundamental possa exercer com maestria a sua função de ensinar as crianças a lerem e a produzirem textos, pois é relevante perceber que o uso efetivo da linguagem abre possibilidades para atuarmos sobre nossos interlocutores, persuadi-los, encantá-los, etc.

Por meio dos dados apresentados é possível inferir que o professor trava uma luta diária entre a situação ideal para o ensino de língua materna e o contexto de sua sala de aula. As dificuldades que mencionam são reflexo de uma realidade complexa: formação inicial deficiente que não os preparou para a reflexão sobre oralidade, variação linguística, ensino de leitura e de produção textual; salas com muitos alunos, material didático muitas vezes ruim, problemas relacionados à indisciplina, dentre outros fatores. Ouvir o professor, trazer à tona as suas dificuldades e as suas necessidades formativas com relação ao ensino de língua materna pode contribuir para a mudança, para o desvelamento de novas práticas de ensino de língua materna que certamente demandarão um professor com mais autonomia para planejar as unidades de ensino, escolher materiais didáticos, a fim de poder trabalhar com alfabetização e letramento como prática social.

\section{REFERÊNCIAS}

BARDIN, L. Análise de conteúdo. Tradução de: RETO, L. A.; PINHEIRO, A. São Paulo: Edições 70, 2011.

BAMBERGER, R. Como incentivar o hábito da leitura. 7. ed. São Paulo: Ática/Unesco, 2008.

BORTONI-RICARDO, S. M.; MACHADO, V. R.; CASTANHEIRA, S. F. Formação do professor como agente letrador. São Paulo: Contexto, 2010.

CAGLIARI, L. C. Alfabetização \& Linguística. São Paulo: Scipione, 2009. 
COLELlO, S. M. G. A escola que não ensina a escrever. São Paulo: Paz e Terra, 2007. COSTA VAL, M. G. et al. Avaliação do texto escolar: professor-leitor/aluno-autor. Belo Horizonte: Autêntica Editora/Ceale, 2009.

CRAHAY, M. Qual pedagogia para os alunos em dificuldade escolar? Cadernos de Pesquisa, São Paulo, n. 130, p. 181-208, jan./abr. 2007.

DOURADO, L. F.; OLIVEIRA, J. F. de; SANTOS, C. de A. (Coord.). A qualidade da educação: conceitos e definições. Brasília: INEP/MEC, 2007.

FERreiro, E.; TEBEROSKY, A. A. Psicogênese da lingua escrita. Porto Alegre: Artes Médicas, 1989.

GERALDI, J. W. (Org.). O texto na sala de aula: leitura e produção. São Paulo: Ática, 2001.

IMBERNÓN, F. Formação docente e profissional: formar-se para a mudança e a incerteza. São Paulo: Cortez, 2005.

JOLIBERT, J. Formando crianças produtoras de textos. São Paulo: Artmed, 2006.

JOLIBERT, J. Caminhos para aprender a ler e a escrever. São Paulo: Contexto, 2008.

KLEIMAN, A. B. Texto e leitor: aspectos cognitivos da leitura. Campinas: Pontes, 1989.

KLEIMAN, A. B. Os significados do letramento: uma nova perspectiva sobre a prática social da escrita. 2. ed. Campinas: Mercado de Letras, 2012.

KOCH, I. V. A coesão textual. 15. ed. São Paulo: Contexto, 2001.

KOCH, I. V.; TRAVAGLIA, L. C. A coerência textual. 4. ed. São Paulo: Contexto, 2008.

LERNER, D. Ler e escrever na escola: o real, o possível e o necessário. Porto Alegre: Artmed, 2002.

LIBÂNEO, J. C. Adeus professor, adeus professora: novas exigências educacionais e profissão docente. São Paulo: Cortez, 2011.

MORAIS, A. G. Ortografia: ensinar e aprender. 5. ed. São Paulo: Ática, 2009.

PARISOTTO, A. L. V. Produção textual e formação docente: uma relação possível. 248 f. Tese (Doutorado em Letras) - Faculdade de Ciências e Letras, Universidade Estadual Paulista "Júlio de Mesquita Filho", Assis, 2004.

PARISOTTO, A. L. V. O olhar docente: aspectos relevantes na correção e avaliação de textos escolares. Estudos Linguísticos, São Paulo, v. 38, n. 2, p. 59-73, maio/ago. 2009.

REALI, A. M. de M. R.; TANCREDI, R. M. S. P. Interação escola-famílias: concepções de professores e práticas pedagógicas. In: REALI, A. M. de M. R.; TANCREDI, R. M. S. P.; MIZUKAMI, M. da G. N. (Org.). Formação de professores: práticas pedagógicas e escola. São Carlos: EdUFSCar, 2002. p. 73-98. 
RODRIGUES, M. A. P. Análise de práticas e de necessidades de formação. Lisboa, Portugal: Direcção-Geral de Inovação e Desenvolvimento Curricular, 2006. (Coleção Ciências da Educação, v. 50).

ROJO, R. Letramentos múltiplos, escola e inclusão social. São Paulo: Parábola, 2009.

SILVA, E. T. Conferência sobre leitura - Trilogia pedagógica. 3. ed. Campinas: Autores Associados, 2006.

SOARES, M. Alfabetização e letramento. São Paulo: Contexto, 2011.

TARDIF, M.; LESSARD, C. (Org.). O oficio do professor. São Paulo: Vozes, 2008.

UNESCO. Organização das Nações Unidas para a Educação, a Ciência e a Cultura. O perfil dos professores brasileiros: o que fazem, o que pensam, o que almejam. São Paulo: Moderna, 2004.

WEISS, M. L. L. Psicopedagogia Clínica: uma visão diagnóstica dos problemas de aprendizagem escolar. Rio de Janeiro: DP \& A, 2004.

Texto recebido em 06 de fevereiro de 2016.

Texto aprovado em 27 de março de 2016. 